\title{
Targeted newborn hearing screening in the neonatal intensive care unit of Assiut University Hospital
}

\author{
Kholoud Mohamed Omar ${ }^{1}$, Enass Sayed Mohamed ${ }^{1}$, Eman Abdel Fattah Said ${ }^{1}$, Nafisa H. R. AbdelAziz ${ }^{2}$ and \\ Maha Abdelgaber A. Aly ${ }^{1 *}$ (D)
}

\begin{abstract}
Background: Early detection of congenital hearing loss $(\mathrm{HL})$ and appropriate intervention is essential to minimize its dramatic impact. Target-based newborn hearing screening (TNHS) was initially targeted high-risk register (HRR) newborn. The advance techniques in neonatology in neonatal intensive care unit (NICU) lead to decrease mortality among low birth weight and preterm infants, but significant morbidities including hearing loss persist. In this study, we aimed to assess the prevalence of hearing loss and the percentage of different risk factors among the HRR neonates admitted to NICU at Assiut University Hospital.
\end{abstract}

Results: The prevalence of hearing loss among the study group is $1 \%$. The most common risk factor present between the study group was prematurity associated with the low birth weight (57\%). The combination of preterm and low birth weight has statistically significant effect on hearing loss $(p<0.006)$. There was statistically significant difference in the pass rate of the transient evoked otoacoustic emission (TEOAE) frequencies included in the screening program. The highest pass rate $91 \%$ and $85 \%$ was at $4 \mathrm{KH}$ and $3 \mathrm{KH}$, respectively, while the least pass rate was at $1 \mathrm{KH}$ (11.5\%).

Conclusion: TEOAE screener is safe, noninvasive, and doesn't require sedation and cost-effective method in the newborn hearing screening at NICU. For HRR, it is better to do screening before hospital discharge so allowing enough time for comorbidities of the neonate to improve. Neonatal hearing screening in high-risk neonates in NICU allows early identification of children with hearing loss with early intervention.

Keywords: Newborn hearing screening, High-risk register, Neonatal intensive care unit

\section{Background}

In many world population, the prevalence of moderate and severe bilateral hearing loss (HL) (> $40 \mathrm{~dB})$ is $2-3$ per 1000 live births in well baby nursery population [1, $2]$ and $2-4$ in 100 infants in an intensive care population [3-5] as reported by Wroblewska-Seniuk et. al. [6]. The most obvious effect of childhood hearing loss is on

\footnotetext{
*Correspondence: mahaabdelgaber@aun.edu.eg

${ }^{1}$ Audiovestibular Medicine Unit, Department of Ear, Nose and Throat, Faculty of Medicine, Assiut University, Kornish Al Ibrahimeya, Asyut 2, Assiut Governorate, Assiut, Egypt

Full list of author information is available at the end of the article
}

language development, but it also has an impact on literacy, self-esteem, and social skills [7-9]. Early detection of congenital HL and appropriate intervention is essential to minimize its dramatic impact $[10,11]$. The Joint Committee on Infant Hearing (JCIH) in 2007 recommended that screening should be completed by 1 month of age, and all infants with hearing loss should be identified by 3 months of age and receive intervention by 6 months of age [11].

The screening for hearing loss must fulfill all the criteria for universal screening. First of all, its prevalence is very high. Secondly, it has severe consequences for the 
affected child and its family if it is not diagnosed early and managed appropriately. Finally, the techniques used to diagnose this problem are relatively inexpensive, easily available, accurate, objective, and reliable [12]. There are two types of newborn hearing screening: (1) target-based newborn hearing screening (TNHS) was initially targeted toward those newborn "at risk" for hearing loss called high-risk register (HRR). (2) Universal newborn hearing screening (UNHS) is based on the principle that all neonates and infants should have access to objective screening to allow for early intervention [13].

In Egypt, UNHS has been implemented in 2019 by Egyptian Ministry of Health. The UNHS protocol in Egypt composed of two stages: first stage is conducted in primary healthcare centers during the days of the national program of thyroid screening using transient evoked otoacoustic emission (TEOAE). Newborns who failed the test rescreened 1 week later by TEOAE in the same centers. The second stage is conducted to diagnose all newborns who failed the second screening of first stage and conducted on audiology clinic in tertiary hospitals of ministry of health. In Assiut Governorate, the diagnostic stage is done on Assiut General Hospital. Before the implantation of the national newborn hearing screening program in 2019, there was no universal or targeted newborn hearing screening programs in Assiut. To our knowledge, there were no studies done to screen newborn hearing loss in Assiut University Hospital or even in Assiut Governorate.

There are many advances in neonatology that have improved outcomes for infants born premature and/or at low birth weight in neonatal intensive care unit (NICU) such as assisted ventilation and extracorporeal membrane oxygenation therapy. These advance techniques lead to decrease mortality among low-birth-weight infants, but significant morbidities including hearing loss persist.

The present study aimed to assess the prevalence of hearing loss and the percentage of different risk factors among the high-risk register neonates admitted to NICU at Assiut University Hospital.

\section{Subjects and methods Subjects}

The study is a prospective cross-sectional study that was conducted on 200 neonates of both sexes who were admitted to NICU at Assiut University Hospital. The 200 neonates considered HRR according to the JCIH 2007 position statement [11]. The research was carried out between March 2020 and January 2021, and informed written consent was obtained from all parents/ guardians of all participants under 16 years old in the study. Ethical approval was obtained by the ethical committee, Faculty of Medicine, Assiut University, Egypt.

\section{Methods}

Each subject was presented to the following:

- 1 Complete history taking include personal history (name, age, sex); prenatal history (infection, drugs, trauma, miscarriage, irradiation); natal history (gestational age and mode of delivery); postnatal history (birth weight, respiratory distress, cyanosis, jaundice, convulsions, cerebral hemorrhage, ototoxic medications intake and its duration, mechanical ventilation and its duration, exchange transfusion, and duration of NICU admission); family history (consanguinity, congenital anomalies, hearing impairment).

- 2 Clinical examination (for any congenital anomalies, external examination of auricles, otoscopic examination for patency and structure of external auditory canal).

- 3 Hearing screening by TEOAE: all neonates were screened by TEOAE, and the results were interpreted according to Rhode Island criteria in which pass result means signal-to-noise ratio $\geq 3 \mathrm{~dB}$ at three distinct frequencies between 1 and $4 \mathrm{kHz}$ ) [14]. The first stage was conducted on 200 neonates, while the second stage was done for only nine neonates who failed the first stage.

- 4. Diagnostic $A B R$ was performed for the neonates who failed the second stage screening, and for the neonates with hyperbilirubinemia, to not miss the auditory neuropathy, after hospital discharge and before age of 3 months at Audiovestibular Medicine Unit, Assiut University Hospital.

\section{Results}

The study included 200 neonates ( $n=400$ ears) of both sexes. They were incubated at NICU of Assiut University Hospital in the period between March 2020 and January 2021. Their demographic data is shown in Table 1.

\section{Risk factors among the study group}

Most of neonates of the study group had multiple risk factors at the same time like prematurity, low birth weight (LBW), and hyperbilirubinemia required blood transfusion (Table 2). The most common combined risk factors of hearing loss were prematurity plus LBW; they were presented together in $57 \%$ of the total neonates, while the most common single risk factor found alone in the study group was the prematurity $(25 \%)$ followed by LBW (10.5\%).

\section{Results of first-stage screening}

One-hundred ninety-one out of 200 neonates (95.5\%) had passed the first-stage screening, and only nine 
Table 1 Demographic data of the study group

\begin{tabular}{lll}
\hline & No. $(\boldsymbol{n}=\mathbf{2 0 0})$ & \% \\
\hline $\begin{array}{ll}\text { Gender } \\
\text { Male }\end{array}$ & 118 & 59 \\
$\quad$ Female & 82 & 41 \\
Age range group & & \\
$\quad<1$ week & 52 & 26 \\
$-1<2$ weeks & 75 & 37.5 \\
$-2<3$ weeks & 33 & 16.5 \\
$-3<4$ weeks & 13 & 6.5 \\
$-4<5$ weeks & 27 & 13.5 \\
Range (min-max) & $2-40$ & \\
Mean \pm SD & $14.5 \pm 9.39$ & \\
Gestational age & & 61.5 \\
$<37$ weeks & 123 & 38.5 \\
$\geq 37$ weeks & 77 & \\
Range (min-max) & $26-40$ & 62 \\
Mean \pm SD & $34.8 \pm 3.5$ & 38 \\
Body weight level & & \\
500 gm-1.7 kg & 124 & 60 \\
$>1.7$ kg & 76 & \\
Delivery & 120 & \\
Cesarean & 80 & \\
Vaginal delivery & & \\
\hline
\end{tabular}

Table 2 Distribution of risk factors among the study group

\begin{tabular}{lll}
\hline Risk factor & No. & \% \\
\hline Preterm & 50 & 25.0 \\
Low BW & 21 & 10.5 \\
Hyperbilirubinemia with blood transfusion & 5 & 2.5 \\
Craniofacial anomalies & 1 & 0.5 \\
Brain anoxia & 1 & 0.5 \\
F.H of HL + preterm + low BW & 1 & 0.5 \\
Preterm + low BW & 114 & 57.0 \\
Preterm + hyperbilirubinemia with blood transfusion & 1 & 0.5 \\
Preterm + craniofacial anomalies & 2 & 1.0 \\
Preterm + low BW + craniofacial anomalies & 1 & 0.5 \\
Preterm + low BW + hyperbilirubinemia with blood & 1 & 0.5 \\
transfusion & & \\
Preterm + low BW + craniofacial anomalies + brain anoxia & 1 & 0.5 \\
Brain anoxia + MV & 1 & 0.5 \\
Total & $\mathbf{2 0 0}$ & $\mathbf{1 0 0 . 0}$
\end{tabular}

$B W$ birth weight, $F H$ family history, $H L$ hearing loss, $M V$ mechanical ventilation

neonates $(4.5 \%)$ had failed the test. Distribution of the risk factors of the study group according to the result of the first-stage screening is shown in Fig. 1.

\section{Tracking of the neonates who failed the first-stage} screening

Four out of nine neonates who failed the first-stage screening succeeded to the second-stage screening, and the other five neonates dropped out after the first stage (4 of them died and one was missed). One of the four neonates passed the second-stage screening and advised to follow up. The other three neonates failed TEOAE and referred for the diagnosis by ABR (Fig. 2). One neonate had a normal hearing sensitivity, and the other two neonates had severe hearing loss. Based on the diagnostic $\mathrm{ABR}$ results, the prevalence of hearing loss in the present study is $1 \%$ ( 2 out of 200 cases).

\section{Neonates with hyperbilirubinemia}

The first-stage screening was carried on seven neonates that have hyperbilirubinemia and blood transfused to them. Five out of the seven passed the 1st stage screening and referred for the diagnosis by ABR, while two neonates did not pass the 1st stage and did not survive to the 2nd stage screening. Four neonates out of the five who passed the 1st stage screening had normal hearing sensitivity and one dropped out (her mother refused to conduct ABR) (Table 3).

\section{Relationship between studied risk factors and $\mathrm{HL}$}

Logistic regression analysis for ABR according to risk factor was done (Table 4) to show the relationship between common risk factors in the study group and the hearing loss. There was statically significant effect of the combination of the risk factors of (prematurity + low birth weight) on hearing loss $(p<0.006)$; this means that the probability of the hearing loss is significant, when the two risk factors combined together in the neonate. Also, there was a statically significant effect of the risk factor of prematurity alone on the hearing loss $(p<0.037)$. Despite the statically significant effect of prematurity alone and (prematurity + low birth weight) on hearing loss, we could not generalize these results as two cases cannot be the cut point used to say highly significant relation between one of high-risk factors and HL.

\section{Pass rate of TEOAE frequencies in the study group}

Five frequencies were counted in during the 1st stage screening by TEOAE $(1,1.5,2,3$, and $4 \mathrm{KH})$. Chi-square test showed no significant difference in pass rate of those frequencies between both ears, while there was a significant difference between the pass rate of frequencies in the same ear $(p<0.001)$; the highest pass rate was on 4 $\mathrm{KH}(91 \%)$ followed by $3 \mathrm{KH}(85 \%)$, and least pass rate was on $1 \mathrm{KH}(11.5 \%)$ (Fig. 3). 


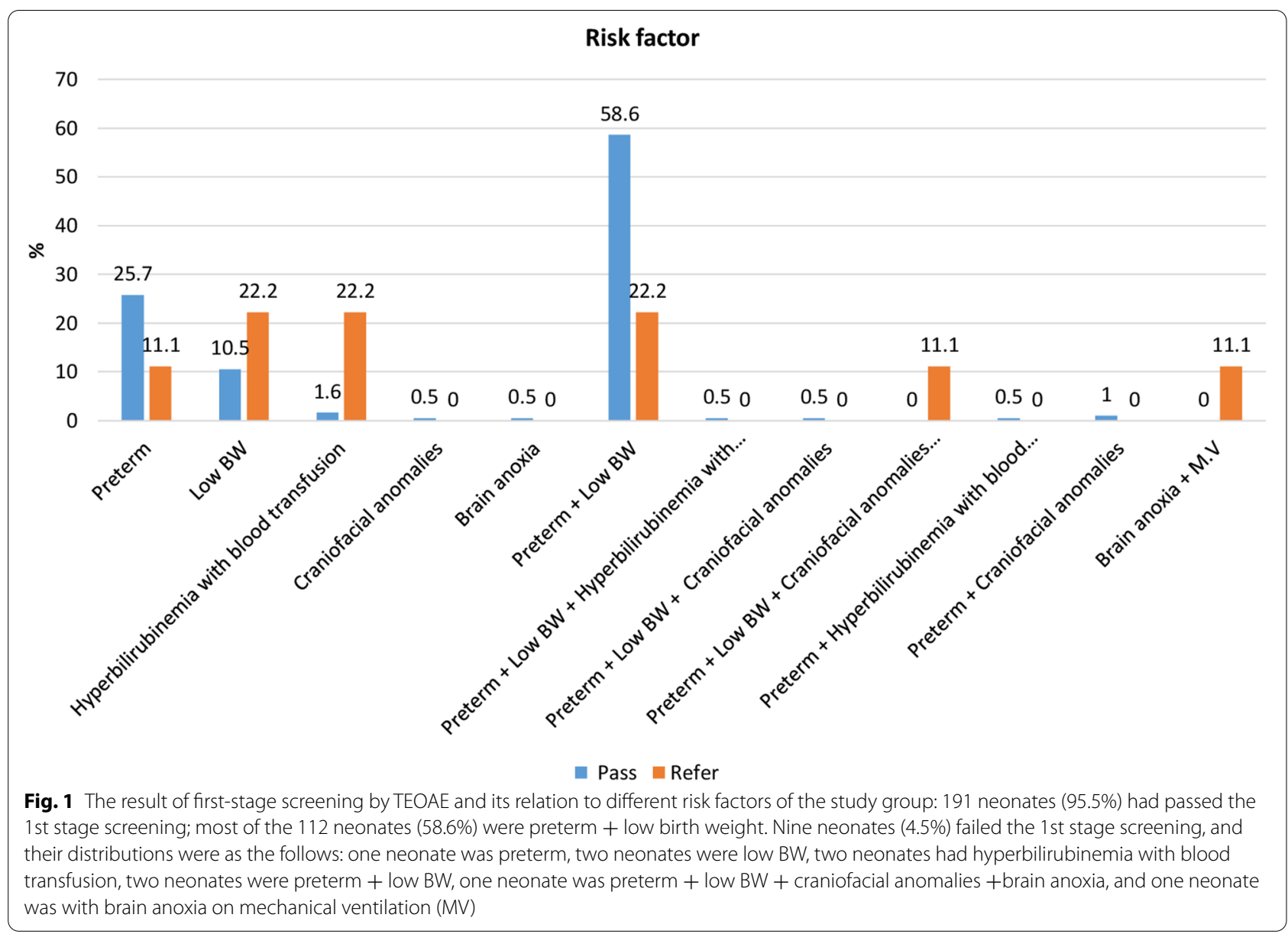

\section{Discussion}

The study was carried out in the form of targeted hearing screening program restricted to a study group of 200 neonates incubated in NICU in the time period between March 2020 and January 2021 and were subjected to risk factors for hearing loss. The most common risk factor in the study was prematurity; total premature neonates were $164(82 \%)$. Prematurity alone as only risk factor was $25 \%$ while combined with low birth weight was $57 \%$ in 114 neonates. Our finding is in accordance with other literature in which prematurity was the most common risk factors among neonates in NICU [15]. On the other hand, our result did not match with other studies in which other risk factors were the major one like severe birth asphyxia and hyperbilirubinemia [16] and ototoxic medications [17]. The difference between the studies in the common risk factors may be due to the variability in environmental conditions surrounding the pregnancy or birth and the difference of medical care between the hospitals.

The probability of hearing loss increases with an increase in the number of risk factors [17]. In our study, there is statically significant effect of the combination of preterm and low birth weight on hearing loss $(p<0.006)$. HL is a severe consequence of prematurity; its prevalence is inversely related to the maturity of the baby. Premature infants have many concomitant risk factors which influence the occurrence of hearing deficit [18]. On another hand, the risk factors for hearing loss in Ohl et al. study were neurological disorders, asphyxia, family history of hearing loss, and TORCH (toxoplasmosis, other agents, rubella, cytomegalovirus, herpes simplex) infection, but hearing loss was not associated with low birth weight or birth before 34 weeks of gestation which is different from our results [19].

In the present study, based on the diagnostic ABR results, the percentage of hearing loss is $1 \%$ ( 2 cases). The prevalence of hearing loss among neonates in NICU is variable in different studies. Some studies reported prevalence close to our results $1.6 \%$ [20], $1.7 \%$ [21], and 0.8 to $2.0 \%$ [22], while others reported higher prevalence 5.09 $\%$ [23], 4,3\% [24], $4.55 \%$ [19], and 4.91\% [25]. The difference in the prevalence of hearing loss might be related to several factors like differences in screening and diagnostic methods of hearing loss [23]; $\mathrm{Hl}$ may be affected by 


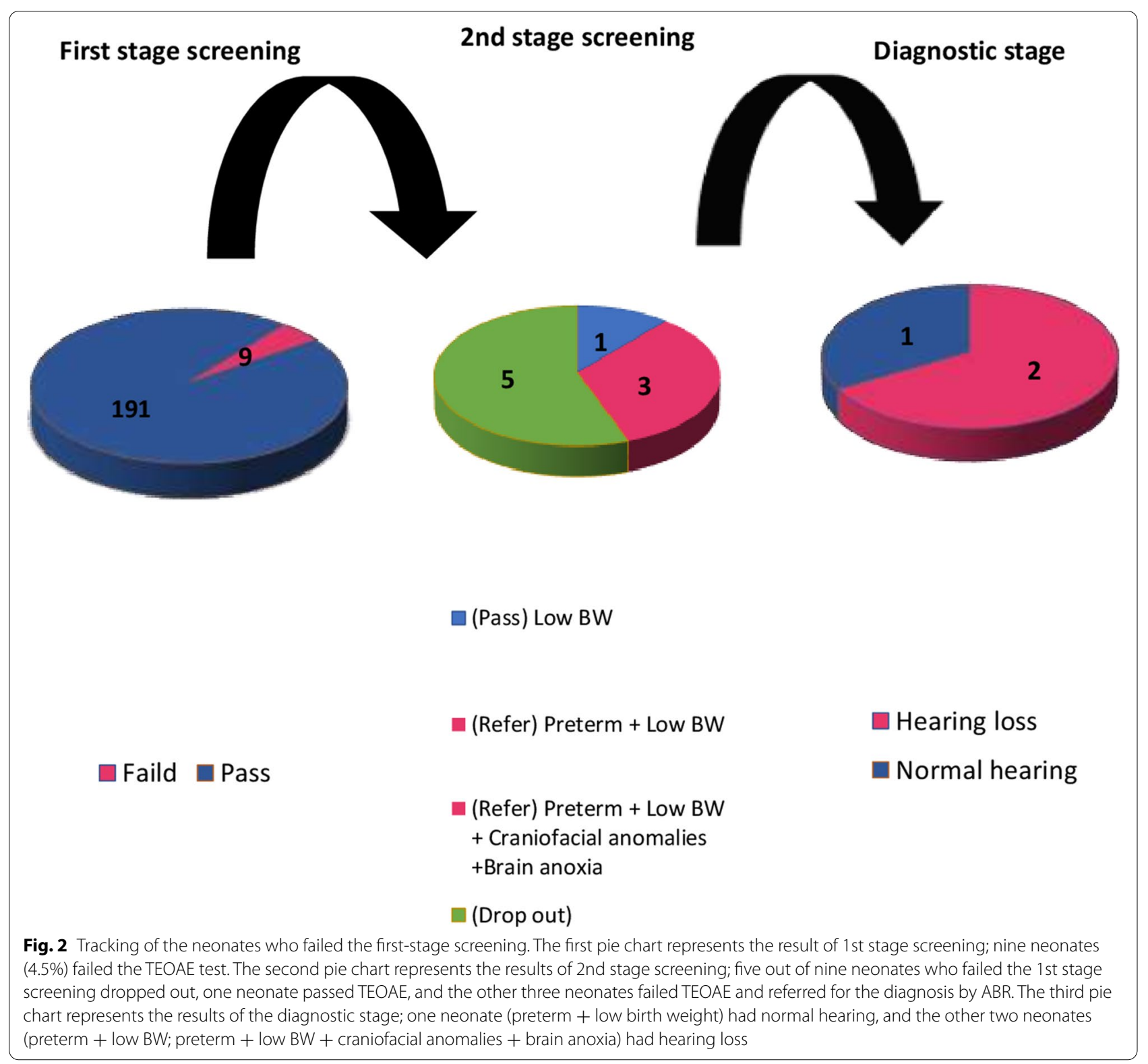

indirect medical factors as the availability and quality of healthcare provisions including birth clinics, NICU, and vaccination programs.

The risk factors for the development of ANSD have been studied in different literatures, and associations have been gathered. Some of the risk factors that have been identified are intracranial hemorrhage, asphyxia, hyperbilirubinemia, prematurity, low birth weight, neonatal ventilation, ototoxic drug exposure, dysmorphic features, Apgar scores, respiratory distress, cytomegalovirus infection, sepsis, meningitis, asphyxia, and family history of hearing loss [26-30]. In the current study, seven neonates $(3.5 \%)$ had hyperbilirubinemia with levels exceeded $20 \mathrm{mg} / \mathrm{dl}$, and all had blood exchange within 24 $h$. The four out of seven who completed the diagnostic test had normal hearing.

Possible explanation that neonates with hyperbilirubinemia in the current study had no auditory neuropathy is the early blood transfusion. These neonates were subjected to blood transfusion early which helped to rapidly decrease the level of the bilirubin in the blood before the affection of the auditory nerve and decrease the possibility of auditory neuropathy spectrum disorder (ANSD) to occur. This agrees with a screening study conducted by Xu et al. (2019) on a group of neonates who met the standard of exchange transfusion 
Table 3 Results of neonates with hyperbilirubinemia required blood transfusion

\begin{tabular}{|c|c|c|c|c|}
\hline \multirow[t]{2}{*}{ Distribution of risk factors } & \multicolumn{2}{|c|}{ First TEOAE } & \multirow{2}{*}{$\begin{array}{l}\text { Drop out }(n=3) \\
\text { No. }\end{array}$} & \multirow{2}{*}{$\begin{array}{l}\text { ABR normal } \\
\text { hearing ( } n \\
=4) \\
\text { No. }\end{array}$} \\
\hline & Pass & Refer & & \\
\hline Hyperbilirubinemia with blood transfusion $(N=5)$ & 3 & 2 & 2 & 3 \\
\hline Preterm + hyperbilirubinemia with blood transfusion $(N=1)$ & 1 & 0 & 0 & 1 \\
\hline Preterm + low BW + hyperbilirubinemia with blood transfusion $(N=1)$ & 1 & 0 & 1 & 0 \\
\hline
\end{tabular}

$B W$, birth weight

Table 4 logistic regression analysis for ABR results according to risk factors

\begin{tabular}{|c|c|c|c|c|}
\hline \multirow[t]{2}{*}{ Risk factor } & \multirow[t]{2}{*}{$\operatorname{EXP}(B)$} & \multicolumn{2}{|c|}{$95 \% \mathrm{Cl}$ for EXP (B) } & \multirow[t]{2}{*}{$P$-value } \\
\hline & & Lower & Upper & \\
\hline Preterm & 18.197 & 1.199 & 276.128 & $0.037^{*}$ \\
\hline Low BW & 2.708 & 0.258 & 28.449 & 0.407 \\
\hline $\begin{array}{l}\text { Hyper bilirubinemia with } \\
\text { blood transfusion }\end{array}$ & 0.129 & 0.006 & 2.681 & 0.186 \\
\hline Preterm + low BW & 16.097 & 2.215 & 116.959 & $0.006^{* *}$ \\
\hline
\end{tabular}

EXP (B): this is the exponentiation of the B coefficient, which is an odds ratio. This value is given by default because odd ratios can be easier to interpret than the coefficient, which is in log-odds unit. Cl: confidence interval of the difference of a numerical field that is expected to contain the true value of a statistical parameter to be known for a population. $B W$, birth weight. *Statistically significant difference $(p<0.05) .{ }^{*}$ Statistically significant difference $(p<0.01)$

and another group of neonates in the same period who did not require exchange transfusion. They found lower incidence of auditory neuropathy in the exchange transfusion group than in the phototherapy group. They also noted that plasma exchange can rapidly reduce serum
UB level to $40-60 \%$ of the original level, and when it is combined with blue light phototherapy, the UB level can be decreased to $60-80 \%$ of original level $24 \mathrm{~h}$ later [31]. So, more attention should be paid on the effective role of blood transfusion in the prevention of auditory neuropathy in the future.

Another point to be mentioned in the current study is the pass rate of the TEOAE frequencies included in the screening program. There was a statistically significant difference between the pass rate of frequencies in the same ear $(p<0.001)$; the highest pass rate was on $4 \mathrm{KH}(91 \%)$ followed by $3 \mathrm{KH}(85 \%)$, and the least pass rate was on $1 \mathrm{KH}(11.5 \%)$. This difference of the pass rate between the frequencies is reported in other screening programs in which higher frequencies (e.g., $2-4$ or $2-5 \mathrm{kHz}$ ) had lower referral rates than lower frequencies $(1-4 \mathrm{kHz})$ [32]. The stiffness of middle ear increases due to reducing the middleear air space by the presence of amniotic fluid and mesenchyme in the middle ear which occurs in early newborn life and therefore affects the transmission

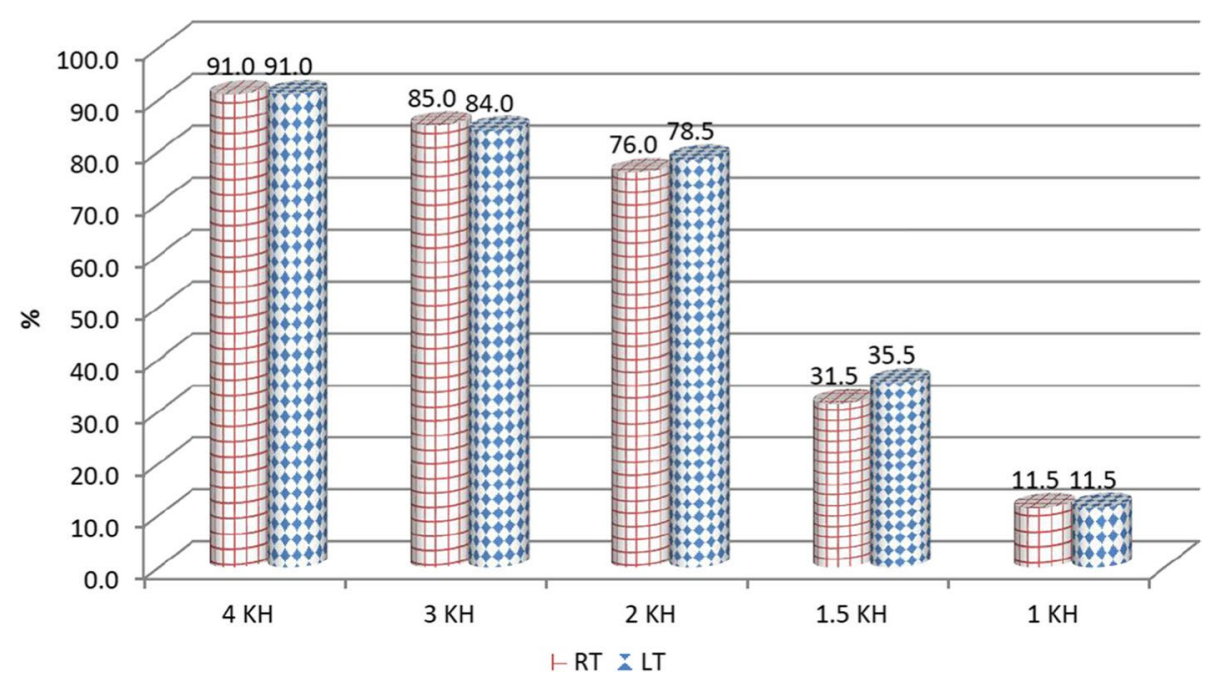

Fig. 3 Distributions of the pass rate of TEOAE frequencies in the study group. There was a significant difference between the pass rate of frequencies in the same ear $(p<0.001)$; the highest pass rate was on $4 \mathrm{KH}(91 \%)$ followed by $3 \mathrm{KH}(85 \%)$, and the least pass rate was on $1 \mathrm{KH}(11.5 \%)$ 
of lower-frequency sounds which can be associated with greater referral rates [33]. So, the use of higher frequencies TEOAE instead of lower frequencies will be valuable to ensure better result of newborn hearing screening.

\section{Conclusions}

In conclusion, we have screened 200 neonates incubated in NICU at Assiut University Hospital in the time period between March 2020 and January 2021. The prevalence of hearing loss is $1 \%$ among the study group. The most common risk factor present between the study group was prematurity associated with the low birth weight (57\%). The combination of preterm and low birth weight has statistically significant effect on hearing loss $(p<$ 0.006 ). There was statistically significant difference in the pass rate of the TEOAE frequencies included in the screening program. The highest pass rate $91 \%$ and $85 \%$ was at $4 \mathrm{KH}$ and $3 \mathrm{KH}$, respectively, while the least pass rate was at $1 \mathrm{KH}(11.5 \%)$.

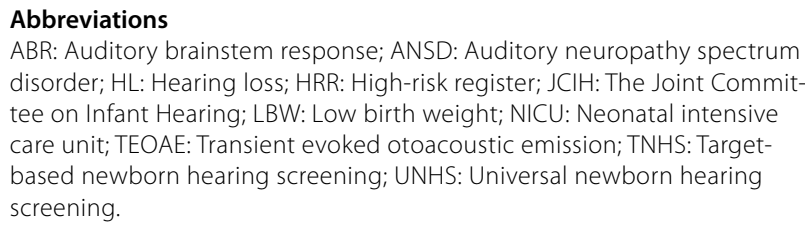

Abbreviations

ABR: Auditory brainstem response; ANSD: Auditory neuropathy spectrum disorder; HL: Hearing loss; HRR: High-risk register; JCIH: The Joint Committee on Infant Hearing; LBW: Low birth weight; NICU: Neonatal intensive care unit; TEOAE: Transient evoked otoacoustic emission; TNHS: Targetbased newborn hearing screening; UNHS: Universal newborn hearing screening.

\section{Acknowledgements}

Not applicable

\section{Authors' contributions}

KMO: patients' interview, gathering and analysis of the results, and writing the main manuscript; ESM, study design and analysis of the results and review the main manuscript; EAFS, study concept and design and analysis of the results and review of the manuscript. NHRAA, study design and patients' interview and review of the manuscript. MAAA: study concept and design, patients'interview, gathering and analysis of the data, and drafting and critical review of manuscript. The author(s) read and approved the final manuscript.

\section{Funding}

Not applicable

\section{Availability of data and materials}

Data generated or analyzed during this study are included in this published article and available from the corresponding author on reasonable request.

\section{Declarations}

\section{Ethics approval and consent to participate}

Informed written consent was obtained from all parents/ guardians of all participants under 16 years old in the study. Ethical approval was obtained by the ethical committee, Faculty of Medicine, Assiut University, Egypt. Approval number (17100662).

\section{Consent for publication}

Not applicable

\section{Competing interests}

The authors declare that they have no competing interests.

\section{Author details}

${ }^{1}$ Audiovestibular Medicine Unit, Department of Ear, Nose and Throat, Faculty of Medicine, Assiut University, Kornish Al Ibrahimeya, Asyut 2, Assiut Governorate, Assiut, Egypt. ${ }^{2}$ Department of Pediatric, Faculty of Medicine, Assiut University, Assiut, Egypt.

Received: 19 November 2021 Accepted: 4 February 2022

Published online: 07 March 2022

\section{References}

1. Mehl AL, Thomson VJP (1998) Newborn hearing screening: the great omission. Pediatrics 101(1):e4-e4

2. Erenberg A, Lemons J, Sia C et al (1999) Newborn and infant hearing loss: detection and intervention. American Academy of Pediatrics. Task Force on Newborn and Infant Hearing, 1998-1999. Pediatrics 103(2):527-530

3. Yoon PJ, Price M, Gallagher K et al (2003) The need for long-term audiologic follow-up of neonatal intensive care unit (NICU) graduates. Int J Pediatr Otorhinolaryngol 67(4):353-357. https://doi.org/10.1016/ s0165-5876(02)00400-7 PubMed PMID: 12663106; eng

4. Hess M, Finckh-Krämer U, Bartsch M et al (1998) Hearing screening in at-risk neonate cohort. Int J Pediatr Otorhinolaryngol 46(1-2):81-89

5. Hille ET, van Straaten HI, Verkerk PH (2007) Prevalence and independent risk factors for hearing loss in NICU infants. Acta paediatrica (Oslo, Norway : 1992) 96(8):1155-1158. https://doi.org/10.1111/j.1651-2227. 2007.00398.x PubMed PMID: 17655618; eng

6. Wroblewska-Seniuk KE, Dabrowski P, Szyfter W et al (2017) Universal newborn hearing screening: methods and results, obstacles, and benefits. Pediatr Res. 81(3):415-422. https://doi.org/10.1038/pr.2016. 250 PubMed PMID: 27861465; eng

7. Yoshinaga-Itano C, Sedey AL, Coulter DK et al (1998) Language of early-and later-identified children with hearing loss. Pediatrics 102(5):1161-1171

8. Figueras B, Edwards L, D L et al (2008) Executive function and language in deaf children. J Deaf Stud Deaf Educ 13(3):362-377

9. Northern JL, Downs MP (2002) Hearing in children. Lippincott Williams \&Wilkins

10. Downs MP, Yoshinaga-Itano C (1999) The efficacy of early identification and intervention for children with hearing impairment. Pediatr Clin North Am 46(1):79-87. https://doi.org/10.1016/s0031-3955(05)70082-1 PubMed PMID: 10079791; eng

11. American Academy of Pediatrics, Joint Committee on Infant Hearing (2007) Year 2007 position statement: principles and guidelines for early hearing detection and intervention programs. Pediatrics 120(4):898-921. https://doi.org/10.1542/peds.2007-2333 PubMed PMID: 17908777; eng

12. Nikolopoulos TP (2015) Neonatal hearing screening: what we have achieved and what needs to be improved. Int J Pediatr Otorhinolaryngol 79(5):635-637

13. Hearing JCol, Pediatrics AAo, Pediatrics AS-L-HAJ (2000) Year 2000 position statement: principles and guidelines for early hearing detection and intervention programs. Am J Audiol 106(4):798-817

14. K. R. White BRVaTRB (1993) Universal newborn hearing screening using transient evoked otoacoustic emissions: results of the Rhode Island hearing assessment project. Sem Hear 14:18-29

15. Di Stadio A, Molini E, Gambacorta V et al (2019) Sensorineural hearing loss in newborns hospitalized in neonatal intensive care unit: an observational study. 23(1):31-36

16. Kumar A, Gupta SC, Sinha VR (2017) Universal hearing screening in newborns using otoacoustic emissions and brainstem evoked response in eastern Uttar Pradesh. Indian J Otolaryngol Head Neck Surg 69(3):296-299. https://doi.org/10.1007/s12070-017-1081-x PubMed PMID: 28929058; eng 
17. Bielecki I, Horbulewicz A, Wolan T (2011) Risk factors associated with hearing loss in infants: an analysis of 5282 referred neonates. Int J Pediatr Otorhinolaryngol 75(7):925-930. https://doi.org/10.1016/j.ijporl. 2011.04.007

18. Wroblewska-Seniuk K, Greczka G, Dabrowski P et al (2017) Hearing impairment in premature newborns-analysis based on the national hearing screening database in Poland. PloS one. 12(9):e0184359. https://doi.org/10.1371/journal.pone.0184359 PubMed PMID: 28910311; eng

19. Ohl C, Dornier L, Czajka C et al (2009) Newborn hearing screening on infants at risk. Int J Pediatr Otorhinolaryngol 73(12):1691-1695 https:// doi.org/10.1016/j.ijporl.2009.08.027

20. Li P-C, Chen W-I, Huang C-M et al (2016) Comparison of newborn hearing screening in well-baby nursery and NICU: a study applied to reduce referral rate in NICU. PloS one. 11(3):e0152028-e0152028. https://doi. org/10.1371/journal.pone.0152028 PubMed PMID: 27023324; eng

21. Mason JA, Herrmann KR (1998) Universal infant hearing screening by automated auditory brainstem response measurement. Pediatrics. 101(2):221-228. https://doi.org/10.1542/peds.101.2.221 PubMed PMID: 9445495; eng

22. Tharpe AM, Seewald R (2016) Comprehensive handbook of pediatric audiology. Plural publishing

23. Hardani AK, Goodarzi E, Delphi M et al (2020) Prevalence and risk factors for hearing loss in neonates admitted to the neonatal intensive care unit: a hospital study. Cureus 12:10

24. Molini E, Calzolaro L, Lapenna R et al (2016) Universal newborn hearing screening in Umbria region, Italy. Int J Pediatr Otorhinolaryngol 82:92-97. https://doi.org/10.1016/j.ijporl.2016.01.007 PubMed PMID: 26857323; eng

25. Rai N, Thakur N (2013) Universal screening of newborns to detect hearing impairment--is it necessary? Int J Pediatr Otorhinolaryngol 77(6):1036-1041. https://doi.org/10.1016/j.ijporl.2013.04.006 PubMed PMID: 23642585; eng

26. Cardon G, Campbell J, Sharma A (2012) Plasticity in the developing auditory cortex: evidence from children with sensorineural hearing loss and auditory neuropathy spectrum disorder. J Am Acad Audiol 23(6):396-411

27. Madden C, Rutter M, Hilbert L et al (2002) Clinical and audiological features in auditory neuropathy. Arch Otolaryngol Head Neck Surg 128(9):1026-1030

28. Bielecki I, Horbulewicz A, Wolan T (2012) Prevalence and risk factors for auditory neuropathy spectrum disorder in a screened newborn population at risk for hearing loss. Int J Pediatr Otorhinolaryngol 76(11):1668-1670. https://doi.org/10.1016/j.ijporl.2012.08.001 PubMed PMID: 22939890; eng

29. Walker E, McCreery R, Spratford M et al (2016) Children with auditory neuropathy spectrum disorder fitted with hearing aids applying the American academy of audiology pediatric amplification guideline: current practice and outcomes. J Am Acad Audiol 27(03):204-218

30. Shapiro SM, Nakamura H (2001) Bilirubin and the auditory system. J Perinatol 21(1):S52-S55

31. Xu J, Weng M, Li N et al (2019) Relationship research between auditory neuropathy spectrum disorder and exchange transfusion in neonates with severe hyperbilirubinemia. Int J Pediatr Otorhinolaryngol 123:146-150. https://doi.org/10.1016/j.ijporl.2019.04.044 PubMed PMID: 31103744 ; eng

32. Akinpelu OV, Peleva E, Funnell WRJ et al (2014) Otoacoustic emissions in newborn hearing screening: a systematic review of the effects of different protocols on test outcomes. Int J Pediatr Otorhinolaryngol 78(5):711-717

33. Ravicz ME, Rosowski JJ, Merchant SN (2004) Mechanisms of hearing loss resulting from middle-ear fluid. Hear Res 195(1):103. https://doi.org/10. 1016/j.heares.2004.05.010

\section{Publisher's Note}

Springer Nature remains neutral with regard to jurisdictional claims in published maps and institutional affiliations.

\section{Submit your manuscript to a SpringerOpen ${ }^{\circ}$ journal and benefit from:}

- Convenient online submission

- Rigorous peer review

- Open access: articles freely available online

- High visibility within the field

- Retaining the copyright to your article

Submit your next manuscript at $\boldsymbol{\nabla}$ springeropen.com 